\title{
PENGARUH SOCIAL MEDIA MARKETING TERHADAP BRAND IMAGE MYPANGANDARAN TOUR AND TRAVEL
}

\author{
Silvy Damayanti \\ Universitas Padjadjaran \\ silvydamayanti98@gmail.com \\ Arianis Chan \\ Universitas Padjadjaran \\ arianis.chan@unpad.ac.id \\ Cecep Safa'atul Barkah \\ Universitas Padjadjaran \\ cecep.barkah@unpad.ac.id
}

\begin{abstract}
Tour \& Travel Agent is an old type of business that can still maintain its potential as a business opportunity every year. This is due to the use of the internet, thus presenting the online travel market. One of the travel agency businesses that use the internet, especially social media, as a marketing medium to build a company brand image is MyPangandaran. However, the growth of followers on the @mypangandarantours Instagram account is relatively slow, and the level of follower engagement is still low. This study aims to find out how MyPangandaran grows a positive brand image for followers of their Instagram account, @mypangandarantours. In addition, to see the influence that social media has had on followers of brand images on their Instagram accounts. The method used in this research is quantitative with the type of associative survey research. The data technique uses analysis from observations, literature studies, interviews and questionnaires. The sample in this study was 96 followers of the @mypangandarantours Instagram account. The sampling technique used non-probability sampling, namely purposive sampling. The data analysis technique used simple linear regression analysis. This study indicates a significant influence of social media on the brand image of followers of the @ mypangandarantours Instagram account, meaning that if the social media marketing variable is getting better, the brand image will be getting better.
\end{abstract}

Keywords: brand image; content sharing; social media marketing; strength of brand association.

\section{PENDAHULUAN}

Dunia bisnis terbagi menjadi dua jenis, yaitu bisnis jasa dan bisnis barang. Bisnis barang maupun jasa, keduanya bertujuan untuk pemenuhan kebutuhan dan keinginan konsumen. Salah satu kebutuhan yang tidak bisa terlepaskan untuk seseorang adalah kebutuhan pergi berlibur. Hal ini menjadi peluang usaha bagi penggiat bisnis di industri tour \& travel agent (Suwena \& Widyatmaja, 2017).

Tour \& travel agent merupakan usaha jenis lama yang masih mampu memertahankan potensinya sebagai peluang usaha yang tetap menjanjikan. Hal ini pun merupakan salah satu faktor yang membuat para pelancong mancanegara datang ke Indonesia dan dengan mudah mencari jasa tour \& travel melalui internet untuk membantu perjalanan mereka. internet digunakan untuk mempermudah pelancong mencari biro perjalanan yang dapat membantu mereka untuk efisiensi waktu liburannya. Jumlah pengguna internet terus meningkat setiap tahunnya. Hampir semua pengguna gadget atau smartphone sudah dapat dengan mudah terhubung ke internet untuk memenuhi berbagai keperluannya. Para pengusaha travel tradisional pun sudah mulai beralih ke pemasaran melalui internet. Berdasarkan data yang diperoleh dari Hootsuite We Are Social tahun 2019 pengguna internet meningkat sebesar 13\% dari tahun 2018 (Kemp, 2019).

Konsumen kini lebih pintar dalam hal pemilihan produk karena konsumen tidak hanya melihat dari segi kualitas maupun harga, tetapi juga dari citra merek yang melekat pada produk yang ingin dikonsumsinya. Citra merek sangat penting bagi keberhasilan produk, karena pada saat pembelian suatu produk, orang akan cenderung membeli mereknya. Merek adalah nama, tanda, simbol, atau 
Damayanti, et al. Pengaruh Social Media Marketing terhadap Brand Image My Pangandaran Tour and Travel

kombinasinya, yang ditunjukkan untuk mengidentifikasi (membedakan) barang atau layanan suatu penjual dari barang dan layanan penjual lainnya (Simamora, 2000). Sedangkan citra merek (brand image) menurut Keller (2013:3) adalah penilaian yang diberikan oleh konsumen atas merek produk tersebut.

Agar konsumen dapat mengetahuinya, diperlukan proses penyampaian informasi melalui komunikasi pemasaran. Salah satu komunikasi pemasaran yang banyak digunakan adalah pemasaran media sosial. Media sosial adalah alat pemasaran yang paling berpengaruh yang telah berevolusi dalam waktu singkat dan memiliki ribuan koneksi yang terpapar ke dalam kegiatan pemasaran tanpa memandang waktu, batas atau wilayah (Lipsman et al., 2012). Selain itu, pengguna media sosial di Indonesia pun sangat banyak. Berdasarkan Kemp (2019), pengguna media sosial di Indonesia mencapai 150 juta atau sebesar 56\% dari total populasi di tahun 2019. Jumlah tersebut naik 20\% dari survei sebelumnya. Sementara pengguna media sosial mobile mencapai 130 juta atau sekitar $48 \%$ dari populasi.

Pelanggan sekarang menggunakan media sosial untuk terhubung, mencari, dan bertukar informasi, pemikiran, dan pengalaman merek dan perusahaan. Seperti yang dikemukakan oleh Li \& Bernoff (2011) platform media sosial menawarkan kesempatan bagi pelanggan untuk berinteraksi dengan konsumen lain sehingga perusahaan tidak lagi menjadi satu-satunya sumber komunikasi merek. Fenomena ini telah mengurangi kontrol pemasar terhadap manajemen merek (Berthon et al., 2007). Profil dan informasi produk dan perusahaan di jaringan media sosial diasumsikan sebagai sumber yang andal dan kredibel, lebih dapat diandalkan dan layak daripada tipe pemasaran tradisional (Bruhn \& Schoenmueller, 2012).

Konsumen akan memberi tahu tujuh hingga sepuluh orang tentang suatu produk dalam pemasaran tradisional, di sisi lain pemasaran media sosial memungkinkan konsumen untuk berbagi pengalaman secara langsung dengan jutaan pengguna media sosial dalam waktu singkat (Mangold \& Faulds, 2009). Media sosial memainkan peran penting dalam membangun merek. Oleh karena itu, sangat penting untuk memahami persepsi pelanggan terhadap merek tidak lagi hanya dipengaruhi oleh apa yang dikomunikasikan oleh perusahaan, tetapi apa yang pelanggan katakan tentang merek tertentu juga. Penyebaran viral informasi di antara penggunai media sosial jauh lebih kuat daripada media tradisional seperti TV, radio, dan iklan cetak (Keller, 2009).

Dari hasil observasi, pemasaran melalui media sosial ini juga dilakukan oleh biro wisata yang ada di Kabupaten Pangandaran. Pangandaran merupakan kabupaten di tenggara provinsi Jawa Barat yang memiliki potensi kepariwisataan dan memiliki banyak obyek wisata. Hal ini menjadi salah satu faktor yang membuat masyarakat melihat peluang untuk berlomba-lomba membuka usaha yang menguntungkan di sekitar kawasan wisata. Salah satunya adalah jasa biro wisata. Biro wisata Pangandaran memiliki asosiasi khusus yang mewadahi mereka, yaitu ATTAP (Asosiasi Tour \& Travel Agent Pangandaran). Ada sekitar 26 pengusaha biro wisata yang menjadi anggota ATTAP dari total 38, yang telah dikukuhkan oleh bupati Pangandaran pada 2017. ATTAP ini di bawah naungan Dinas Pariwisata Pangandaran, KOMPEPAR (Komunitas Penggerak Pariwisata). Salah satu biro wisata yang menjadi anggotanya adalah MyPangandaran.

Hasil wawancara dengan tim pemasaran MyPangandaran menjelaskan bahwa MyPangandaran memiliki konsep "top travel with the best deal" yang berarti MyPangandaran menyediakan penawaran terbaik untuk menemani perjalanan liburan konsumennya. Bukan hanya itu, MyPangandaran adalah salah satu dari 6 agensi biro perjalanan yang mewakili Kabupaten Pangandaran di ASITA (Association of The Indonesian Tour and Travel Agencies). Pada awalnya MyPangandaran merupakan media yang memasarkan potensi wisata di Pangandaran melalui media sosial, khususnya Instagram.

Observasi awal menunjukkan pertumbuhan jumlah followers MyPangandaran cenderung lambat. Akun Instagram MyPangandaran dibuat pada tahun 2014 akan tetapi jumlah followers hanya 2.329. Sedangkan MyPangandaran adalah salah satu usaha tour \& travel yang melakukan pemasaran secara aktif dan berada pada pencarian teratas di mesin pencarian jika konsumen mencari informasi tentang 
Pangandaran. Hasil survei awal menyatakan variabel brand image di MyPangandaran sudah tersampaikan dan dapat diterima dengan baik oleh konsumen.

Penelitian terdahulu mengindikasikan terdapat beberapa faktor yang berpengaruh terhadap brand image. Bilgin (2018) mengemukakan kegiatan pemasaran media sosial adalah faktor yang efektif pada citra merek dan loyalitas merek. Selanjutnya Agmeka et al (2019) menjabarkan bahwa alur discount framing memengaruhi purchase intention dan actual behaviour bergantung pada brand reputation dan brand image. Mileva dan Fauzi (2018) memaparkan bahwa content creation, content sharing, connecting dan community building berpengaruh secara simultan dan signifikan terhadap struktur keputusan pembelian. Seo dan Park (2018) menjelaskan trendiness adalah komponen social media marketing yang paling penting, dan social media marketing activities berpengaruh signifikan terhadap kesadaran merek dan citra merek. Berdasarkan uraian di atas, tujuan penelitian ini duntuk mengetahui seberapa besar pengaruh social media marketing terhadap brand image yang dilakukan oleh My Pangandaran Tour and Travel pada followers akun Instagram @mypangandarantours.

\section{KAJIAN PUSTAKA DAN PENGEMBANGAN HIPOTESIS}

\section{Sosial Media Marketing}

Pemasaran media sosial didefinisikan sebagai proses di mana perusahaan membuat, mengkomunikasikan, dan menyampaikan penawaran pemasaran online melalui platform media sosial untuk membangun dan memelihara hubungan pemangku kepentingan yang meningkatkan nilai pemangku kepentingan dengan memfasilitasi interaksi, berbagi informasi, menawarkan rekomendasi pembelian yang dipersonalisasi, dan word of mouth di antara para pemangku kepentingan tentang produk dan layanan yang ada dan sedang tren (Yadav \& Rahman, 2017). Pemasaran media sosial merupakan salah satu strategi pemasaran yang digunakan oleh pelaku bisnis yang sukses agar dapat menjadi bagian dari jaringan konsumen online (Elaydi, 2018). Selain itu, digital word of mouth mendorong pemasaran media sosial menjadi fenomena pemasaran yang berkembang pesat (Rayat et al., 2017).

Brogan (2010:11) mendefinisikan media sosial adalah seperangkat alat komunikasi dan kolaborasi baru yang memungkinkan banyak jenis interaksi yang sebelumnya tidak tersedia untuk orang biasa. Sedangkan menurut Gunelius (2011:10) social media marketing adalah segala bentuk pemasaran langsung atau tidak langsung yang digunakan untuk membangun kesadaran, pengakuan, dan tindakan untuk suatu merek, bisnis, produk, orang, atau entitas lain dan dilakukan dengan menggunakan alatalat web sosial.

Ada beberapa social media marketing yang populer di masyarakat, seperti Facebook, Twitter, Pinterest, Reddit, Youtube, Myspace, Digg, Google Plus, Linkedin, dan Instagram. Setiap sosial media yang digunakan memiliki tata cara pemakaian yang berbeda-beda, seperti Instagram yang hanya dapat membagikan foto dan video yang dapat di isi dengan link, keterangan, tag, dan hahstag. (Grant, 2021)

Menurut Gunelius (2011:59-62), terdapat empat elemen yang dijadikan sebagai dimensi kesuksesan social media marketing. (1) Content creation, konten yang menarik menjadi landasan strategi dalam melakukan pemasaran media sosial. Konten yang dibuat harus menarik serta harus mewakili kepribadian dari sebuah bisnis agar dapat dipercaya oleh target konsumen. (2) Content sharing, membagikan konten kepada komunitas sosial dapat membantu memerluas jaringan sebuah bisnis dan memerluas online audience. Berbagi konten dapat menyebabkan penjualan tidak langsung dan langsung tergantung pada jenis konten yang dibagikan. (3) Connecting, jejaring sosial memungkinkan seseorang bertemu dengan lebih banyak orang dan hubungan yang terjalin antara pemberi dan penerima pesan. Jaringan yang luas dapat membangun hubungan yang dapat menghasilkan lebih banyak bisnis. Komunikasi yang jujur dan hati-hati harus diperhatikan saat melakukan social networking. (4) Community building, web sosial merupakan sebuah komunitas online besar di mana terjadi interaksi antar manusia yang tinggal di seluruh dunia dengan menggunakan teknologi. 
Damayanti, et al. Pengaruh Social Media Marketing terhadap Brand Image My Pangandaran Tour and Travel

Membangun komunitas di internet yang memiliki kesamaan minat dapat terjadi dengan adanya social networking.

\section{Brand Image (Citra Merek)}

Para pemasar membangun merek dengan sebuah konsep yang matang dan digunakan secara maksimal dalam tindakan pemasaran. Salah satu cara untuk membuat merek yang kuat adalah dengan pembentukan citra merek yang baik. Citra yang baik akan memberikan nilai tambah terhadap sebuah produk dan layanan jasa yang berujung pada peningkatan keinginan pembelian konsumen (Mambu, 2015). Sedangkan citra merek menurut Keller (2013:72) adalah persepsi konsumen tentang suatu merek, seperti yang tercermin dari asosiasi merek yang ada dalam ingatan konsumen. Dengan kata lain, asosiasi merek adalah berbagai informasi yang terhubung dalam memori dan mengandung makna merek bagi konsumen. Asosiasi datang dalam berbagai bentuk dan dapat mencerminkan karakteristik produk atau aspek.

Citra merek juga dikaitkan dengan keyakinan dan persepsi yang dianut oleh konsumen tentang suatu merek (Foster, 2016). Persepsi konsumen terhadap produk berdasarkan citra merek di mana citra merek yang lebih tinggi memiliki kualitas dan nilai yang lebih baik. Persepsi konsumen terhadap citra merek produk begitu kuat sehingga produk yang memiliki citra merek tinggi dianggap memiliki kualitas dan nilai yang lebih baik, serts meningkatkan niat konsumen untuk berbelanja produk dengan citra merek yang tinggi (Sallam, 2016).

Pemasar akan berkenaan dengan beberapa program pemasaran untuk mencapai citra merek yang baik dan positif dengan membentuk strength, favourability, dan uniqueness of brand associations guna mentransfer sebuah brand ke memori konsumen. Strength of brand association (kekuatan asosiasi merek) adalah seberapa kuat seseorang terpikir tentang informasi suatu brand diantaranya logo dan nama brand, serta bagaimana memproses segala informasi yang diterima konsumen dan bagaimana informasi tersebut dikelola oleh data sensoris di otak sebagai bagian dari brand image. Favourability of brand association yaitu keunggulan asosiasi merek yang dapat membuat konsumen percaya bahwa atribut dan manfaat suatu merek dapat memuaskan kebutuhan dan keinginan konsumen sehingga menciptakan sikap yang positif terhadap merek tersebut. Uniqueness of brand association ialah inti dari brand association yaitu bahwa merek memiliki keuntungan bersaing yang terus-menerus atau unique selling proposition yang memberikan alasan yang menarik bagi konsumen mengapa harus membeli merek tersebut (Keller, 2013:78).

\section{Hubungan Antar Variabel}

Social media marketing activities memiliki pengaruh pada brand image, loyalitas merek, dan kesadaran merek (Bilgin, 2018). Namun, pengaruh yang paling jelas hanya terlihat pada kesadaran merek. Selain itu, kesadaran merek dan brand image memiliki pengaruh signifikan terhadap loyalitas merek.

Trendiness adalah komponen social media marketing yang paling penting, di mana social media marketing activities berpengaruh signifikan terhadap kesadaran merek dan brand image (Seo dan Park, 2018). Selanjutnya, kesadaran merek secara signifikan memengaruhi komitmen, serta brand image secara signifikan memengaruhi word-of-mouth dan komitmen online.

Content creation, content sharing, connecting dan community building berpengaruh secara simultan dan signifikan terhadap struktur keputusan pembelian (Mileva \& Fauzi, 2018). Kemudian variabel content creation, content sharing, connecting dan community building masing-masing berpengaruh secara parsial dan signifikan terhadap struktur keputusan pembelian. Mileva \& Fauzi (2018) juga menunjukkan bahwa social media marketing adalah alat pemasaran yang sangat efektif. Namun masih belum menjelaskan pengaruh social media marketing terhadap brand image.

H1: Social media marketing berpengaruh signifikan terhadap brand image perusahaan tour and travel. 


\section{METODE PENELITIAN}

Metode penelitian yang digunakan adalah kuantitatif dengan jenis penelitian survei bersifat asosiatif. Populasi pada penelitian ini adalah followers akun Instagram @ mypangandarantours yang berjumlah 2.329 pengikut per 23 Desember 2019. Teknik pengambilan sampelnya menggunakan non-probability sampling yaitu purposive sampling dengan kriteria pengikut akun Instagram @ mypangandarantours dan berusia di atas 17 tahun. Hal ini sesuai dengan target pasar perusahaan yaitu pengguna sosial media aktif yang berusia di atas 17 tahun. Teknik penentuan sampel minimum menggunakan rumus Slovin dengan taraf kepercayaan sampel terhadap populasi 90\% atau tingkat kesalahan 10\%, maka jumlah sampel yang diambil sebanyak 96 orang responden. Sedangkan teknik pengumpulan data yang digunakan adalah angket (kuesioner) dengan skala Likert, wawancara, studi pustaka dan observasi. Penelitian ini mengadopsi dari Gunelius (2011:10) untuk mengukur variabel social media marketing menggunakan 14 item pernyataan. Sedangkan pengukuran variabel brand image menggunakan 14 item pernyataan yang diadopsi dari Keller (2013:72). Selanjutnya, aalisa data menggunakan teknik regresi linier sederhana dengan uji hipotesis terdiri dari uji $\mathrm{T}$ dan koefisien determinasi (Ghozali, 2012).

\section{HASIL DAN PEMBAHASAN}

\section{Uji Validitas dan Reliabilitas}

Suatu kuesioner dikatakan valid jika pernyataan pada kuesioner mampu mengungkapkan sesuatu yang akan diukur oleh kuesioner tersebut serta memiliki nilai koefisien validitas yang lebih besar dari nilai r-tabel dengan:

$\mathrm{df}=\mathrm{n}-2$.

Berdasarkan rumus di atas diperoleh df sebesar 28, dengan $\alpha(0,05)$. Hasil uji validitas instrumen penelitian mengenai variabel social media marketing dan brand image menggunakan metode korelasi Pearson product moment dengan bantuan Software SPSS v21, diperoleh informasi bahwa nilai koefisien validitas (r-hitung) dari setiap item pernyataan pada variabel penelitian lebih besar dari $\mathrm{r}$ tabel $(0,361)$. Hal tersebut menunjukkan semua butir pernyataan yang mewakili variabelnya masingmasing sudah valid dan layak digunakan sebagai alat ukur penelitian.

Alat ukur juga harus memiliki reliabilitas atau keandalan. Suatu alat ukur dapat dikatakan andal jika alat ukur tersebut digunakan berulang kali dan memberikan hasil yang relatif sama. Dalam penelitian ini, untuk menguji tingkat konsistensi dari alat ukur penelitian digunakan Cronbach's Alpha. Suatu konstruk dapat diterima jika memilki nilai koefisien reliabilitas yang lebih besar atau sama dengan 0,6 . Dari kedua variabel yang diteliti, diperoleh nilai koefisien reliabilitas sebesar 0,871 dan 0,948. Kedua nilai koefisien reliabilitas tersebut lebih besar dari 0,60, menyatakan bahwa alat ukur yang digunakan sudah reliabel atau dapat diandalkan.

\section{Karakteristik Responden}

Sebagian besar dari responden yang diteliti adalah laki-laki sebanyak $51,0 \%$ dan sisanya perempuan sebanyak 49,0\%.Pada kategori usia, mayoritas responden berusia 17-25 tahun sebanyak 66,7\% diikuti responden berusia 25-30 tahun sebanyak 20,8\% dan berusia> 30 tahun sebanyak 12,5\%. Sedangkan pada kategori pekerjaan, sebagian besar responden adalah mahasiswa sebanyak $44,8 \%$ dan paling sedikit adalah pelajar sebanyak $2,1 \%$. Hal ini sejalan dengan apa yang ditargetkan sebagai konsumen oleh MyPangandaran.

\section{Uji Normalitas}

Uji normalitas pada model regresi digunakan untuk menguji apakah nilai residual yang dihasilkan dari regresi terdistribusi secara normal atau tidak. Model regresi yang baik adalah yang memiliki nilai residual yang terdistribusi secara normal. Uji normalitas data menggunakan metode grafik yaitu dengan melihat penyebaran data pada sumber diagonal pada grafik normal probability plot ( $P-P$ Plot 
Damayanti, et al. Pengaruh Social Media Marketing terhadap Brand Image My Pangandaran Tour and Travel

of Regression Standardized residual) dan Kolmogorov-Smirnov. Sebagai dasar pengambilan keputusannya, jika titik-titik menyebar sekitar garis dan mengikuti garis diagonal, serta nilai probabilitas (asymtotic significance) lebih besar dari 0,05 maka data residual tersebut telah normal.

Berdasarkan hasil grafik normalitas menggunakan normal p-plot, diketahui bahwa titik-titik menyebar mengikuti garis diagonal yang menunjukkan bahwa model regresi memenuhi asumsi normalitas dan berdasarkan hasil uji Kolmogorov-Smirnov diperoleh nilai probabilitas (Asymp. Sig. (2-tailed)) sebesar 0,331. Nilai signifikansi ( $p$-value) tersebut lebih besar dari 0,05 , sehingga data model regresi sudah berdistribusi normal.

\section{Uji Heteroskedastisitas}

Uji ini bertujuan untuk mengetahui apakah dalam model regresi terjadi kesalahan atau ketidaksamaan variance pada residual (error) dari suatu pengamatan ke pengamatan lain. Untuk menguji adanya gejala heteroskedastisitas digunakan pengujian dengan metode scatter plot dan uji Glejser yaitu dengan meregresikan variabel bebas terhadap nilai absolut dari residual.

Berdasarkan hasil uji scatter plot diketahui titik-titik yang diperoleh menyebar secara acak dan tidak membentuk suatu pola tertentu atau menyebar di atas dan di bawah angka nol pada sumbu Y. Hasil uji heteroskedastisitas dengan metode Glejser diperoleh informasi bahwa nilai signifikansi (Sig.) pada variabel bebas tersebut lebih besar dari taraf signifikansi $(0,120>0,05)$, sehingga tidak ditemukan masalah heteroskedastisitas. Berdasarkan uji asumsi di atas, diketahui bahwa semua pengujian data tidak ditemukan adanya pelanggaran asumsi, sehingga data dapat dianalisis menggunakan analisis regresi linier sederhana.

\section{Persamaan Regresi Linier Sederhana}

Analisis persamaan regresi linier sederhana pada penelitian ini menggunakan bantuan dengan software SPSS v.21. Berdasarkan hasil output SPSS, terlihat nilai koefisien regresi pada nilai Unstandardized Coefficients " $B$ ”, sehingga diperoleh persamaan (2).

$\mathrm{Y}=3,357+0,916 \mathrm{X}$

Persamaan (2) menunjukkan nilai konstanta sebesar 3,357, memiliki arti bahwa jika variabel bebas yakni social media marketing bernilai 0 (nol) dengan kata lain tidak ada perubahan, maka diprediksikan brand image akan bernilai sebesar 3,357. Nilai social media marketing sebesar 0,916, memiliki arti bahwa jika social media marketing mengalami peningkatan sebesar 1 atau semakin baik, maka diprediksikan brand image akan meningkat sebesar 0,916. Sehingga dari persamaan tersebut dapat diprediksikan semakin baiknya social media marketing akan diikuti oleh semakin baiknya brand image perusahaan tour and travel pada followers akun media sosial Instagram @ mypangandarantours.

Tabel 1.

KOEFISIEN REGRESI LINIER SEDERHANA

\begin{tabular}{|c|c|c|c|c|c|c|}
\hline & \multirow[t]{2}{*}{ Model } & \multicolumn{2}{|c|}{$\begin{array}{c}\text { Unstandardized } \\
\text { Coefficients }\end{array}$} & \multirow{2}{*}{$\begin{array}{c}\text { Standardized } \\
\text { Coefficients } \\
\text { Beta }\end{array}$} & \multirow[t]{2}{*}{$t$} & \multirow[t]{2}{*}{ Sig. } \\
\hline & & $B$ & Std. Error & & & \\
\hline \multirow[t]{2}{*}{1} & $\begin{array}{l}\text { (Constant) Social } \\
\text { Media Marketing }(X)\end{array}$ & 3,357 & 3,397 & & ,988 & ,326 \\
\hline & & ,916 & ,073 & ,792 & 12,577 & , 000 \\
\hline & Dependent Variable: $b r$ & limage & & & & \\
\hline
\end{tabular}

Sumber: Output SPSS v.21 


\section{Analisis Koefisien Korelasi (R)}

Hasil nilai korelasi (R) yang diperoleh dengan bantuan Software SPSS v21 antara social media marketing dengan brand image adalah sebesar 0,792. Nilai 0,792 menurut Sugiono (2014:184) berada pada interval 0,60-7,99 termasuk kategori kuat dengan arah positif. Sehingga dapat diketahui terdapat hubungan positif yang kuat antara social media marketing dengan brand image, di mana semakin baik social media marketing maka akan diikuti semakin baiknya brand image perusahaan tour and travel pada followers akun media sosial Instagram @ mypangandarantours begitupun sebaliknya.

\section{Analisis Koefisien Determinasi $\left(\mathbf{R}^{2}\right)$}

Koefisien determinasi $\left(\mathrm{R}^{2}\right)$ merupakan alat untuk mengukur seberapa jauh kemampuan model dalam menerangkan variasi variabel dependen (Ghozali, 2012:97). Hasil statistik menunjukkan nilai $\mathbf{R}^{2}$ sebesar 0,627 atau $62,7 \%$. Hal ini berarti brand image sebesar $62,7 \%$ bisa dijelaskan oleh social media marketing dan sisanya sebesar $37,3 \%$ dijelaskan atau ditentukan oleh variabel lain yang tidak diteliti.

\section{Pengujian Hipotesis (Uji t)}

Berdasarkan hasil output SPSS, diperoleh nilai $t_{\text {hitung }}$ untuk variabel social media marketing terhadap brand image sebesar 12,577 dan nilai p-value (Sig.) sebesar 0,000. Dikarenakan nilai $t_{\text {hitung }}$ lebih besar dari nilai $\mathrm{t}_{\text {tabel }}(12,577>1,986)$ dan nilai signifikansi $0,000<0,05, \mathrm{H} 1$ terbukti. Artinya, social media marketing berpengaruh signifikan terhadap brand image perusahaan tour and travel pada followers akun Instagram @ mypangandarantours.

\section{Pengaruh Social Media Marketing terhadap Brand Image}

Social media marketing terbukti berpengaruh terhadap brand image. Pemasaran media sosial dapat mencakup taktik spesifik seperti membuat konten menarik atau bisa mencakup inisiatif pengembangan merek yang lebih luas seperti berkomunikasi dengan orang-orang. Terdapat empat elemen yang dijadikan sebagai kunci kesuksesan social media marketing yaitu content creation, content sharing, connecting dan community building. Pada My Pangandaran ini social media marketing dilakukan menggunakan Instagram, dengan akun Instagram @ mypangandarantours yang dibuat pada tahun 2014. MyPangandaran melakukan pembuatan konten penawaran paket produk berwisata, informasi tempat wisata dan keadaan aktivitas masyarakat di Pangandaran. Keberagaman konten yang dibagikan tersebut dibuat semenarik mungkin tapi tetap mudah dipahami untuk para pengikutnya.

Tanggapan responden terhadap social media marketing pada followers akun media sosial Instagram @ mypangandarantours sudah tergolong baik dengan presentase tertinggi berada pada dimensi content sharing. Hal ini sejalan dengan Gunelius (2011:60) bahwa berbagi konten dapat mengarah pada penjualan langsung, sedangkan yang terakhir dapat menghasilkan peningkatan kesadaran merek, citra merek, dan loyalitas merek, yang dapat mengarah pada penjualan tidak langsung. Hal ini dapat diartikan bahwa content sharing menimbulkan peluang yang baik untuk mendapatkan perhatian dan diingat oleh pemirsa online serta dapat mengarah pada penjualan tidak langsung dan langsung. Content sharing dapat membantu memerluas jaringan sebuah bisnis dan memerluas pemirsa online.

Berdasarkan hasil wawancara, responden berpendapat bahwa konten yang dibagikan oleh @ mypangandarantours dapat dilihat dan diingat dengan mudah oleh para followers. Hal ini dikarenakan mereka menyebutkan yang terpenting ketika mereka ingin berbelanja atau mencari informasi melalui media sosial adalah akun Instagram mudah diakses atau tidak bersifat private. Pernyataan ini sejalan dengan mayoritas jawaban sangat setuju dari responden. Sehingga siapa pun bisa melihat akun perusahaan artinya perusahaan telah memerluas jaringan pemirsa secara online. Ini artinya secara tidak langsung MyPangandaran telah memenuhi salah satu hal yang disukai oleh pasar ketika menggunakan media sosial.

MyPangandaran telah menjadikan Instagram sebagai sarana yang digunakan untuk pembagian kontennya kepada pemirsa online sehingga dapat menyebabkan para responden yang merupakan 
Damayanti, et al. Pengaruh Social Media Marketing terhadap Brand Image My Pangandaran Tour and Travel

followers akun Instagramnya menerima content sharing dengan sangat baik. Hasil ini sesuai dengan Karman (2015) dan Nurfitriani (2016) bahwa content sharing merupakan bagian dari social media marketing. Content Sharing dijadikan sebagai indikator dalam penelitian Karman (2015) dan Nurfitriani (2016) sedangkan dalam penelitian ini content sharing dijadikan sebagai dimensi dari variabel independen.

Selanjutnya hal yang dilihat oleh konsumen ketika ingin mengikuti suatu brand adalah cerminan positif citra merek pada perusahaan. Citra merek telah menjadi sebuah tantangan utama, karena citra merek mengacu pada pemilihan konsumen akan sebuah produk atau layanan jasa. Citra yang baik akan memberikan nilai tambah terhadap sebuah produk dan layanan jasa yang berujung pada peningkatan keinginan pembelian konsumen (Sallam, 2016). Terdapat tiga elemen yang dapat digunakan untuk pengukuran citra merek, yaitu strength, favourability, dan uniqueness of brand association dalam mentransfer sebuah brand ke dalam memori konsumen. Pada My Pangandaran Tour ini sendiri memiliki konsep "top travel with the best deal" yang berati My Pangandaran Tour menyediakan penawaran terbaik untuk menemani perjalanan liburan terbaik calon konsumennya, di mana untuk mengkomunikasikan hal tersebut My Pangandaran membuat merek yang mudah untuk diingat oleh konsumen.

Tanggapan responden terhadap brand image pada followers akun media sosial Instagram @mypangandarantours sudah tergolong baik dengan persentase tertinggi berada pada dimensi strength of brand association. Hasil penelitian ini mendukung penelitian (Anizir \& Wahyuni, 2017) yang menjadikan brand image sebagai variabel dependen dengan menggunakan 3 dimensi yang sama.

Menurut Keller (2009), untuk memiliki citra yang baik sebuah produk harus mudah dikenali, memiliki reputasi yang baik, dan mudah diingat. Ketika konsumen secara aktif memikirkan dan menguraikan arti informasi pada suatu produk atau jasa maka akan tercipta asosiasi yang semakin kuat pada ingatan konsumen. MyPangandaran Tour membuat kekuatan asosiasi merek dengan mendesain dan membuat merek yang paling sederhana agar dapat dengan mudah diterima, diucapkan dan dibedakan dari pesaing oleh pasar.

Penelitian ini sejalan dengan Seo \& Park (2018) yang memaparkan bahwa pemasaran melalui sosial media yang aktif dan agresif dapat berkontribusi terhadap penciptaan nilai merek dan Bilgin (2018) yang menyatakan aktivitas social media marketing berpengaruh signifikan terhadap brand awareness konsumen, brand image dan brand loyalty. Selanjutnya, penelitian Kristiani dan Dharmayanti (2017) menunjukkan bahwa social media marketing memiliki pengaruh terhadap brand image. Beberapa penelitian lain juga menunjukkan social media marketing memiliki pengaruh terhadap brand image (Bilgin, 2018; Perera \& Perera, 2016; Wijaya \& Putri, 2013).

\section{KESIMPULAN}

Dimensi yang berkontribusi paling besar dalam memengaruhi social media marketing yang dirasakan oleh responden adalah dimensi content sharing. Konsep citra merek My Pangandaran yaitu "top travel with the best deal" dengan dimensi yang berkontribusi paling tinggi dan menjadi kekuatan My Pangandaran Tour adalah dimensi strength of brand association. Secara statistik social media marketing berpengaruh positif signifikan terhadap brand image, di mana semakin baik social media marketing akan diikuti oleh semakin baiknya brand image perusahaan tour and travel pada followers akun Instagram @ mypangandarantours.

Dari penilitian ini terlihat dimensi mana saja yang masih belum tergolong dalam kategori sangat baik pada variabel social media marketing atau pun pada variabel brand image. Hal ini dapat menjadi masukan bagi perusahaan untuk bisa meningkatkan dimensi tersebut dengan memerhatikan setiap item pernyataan yang masih belum tergolong sangat baik. Selain itu, juga sebagai bahan kajian atau evaluasi untuk pembuatan strategi social media marketing perusahaan selanjutnya. Pada akhirnya diharapkan meningkatkan engangement dan followers akun Instagram @ mypangandarantours dengan 
tetap mempertahankan content sharing karena dimensi ini yang menjadi kekuatan perusahaan untuk bisa mendapatkan citra merek yang baik dan positif.

Platform social media yang digunakan pada penelitian ini hanya Instagram saja. Penelitian selanjutnya dapat membandingkan beberapa platform social media agar lebih terlihat jelas social media mana yang lebih efektif dan diinginkan oleh konsumen terkait pemasaran produk atau jasa yang ditawarkan perusahaan. Selain itu, penelitian selanjutnya dapat memertimbangkan untuk menambah variabel lain seperti minat beli atau keputusan pembelian.

\section{DAFTAR PUSTAKA}

Aghekyan-Simonian, M., Forsythe, S., Kwon, W. S., \& Chattaraman, V. (2012). The Role of Product Brand Image and Online Store Image on Perceived Risks and Online Purchase Intentions for Apparel. Journal of Retailing and Consumer Services, 19(3), 325-331. https://doi.org/https://doi.org/10.1016/j.jretconser.2012.03.006

Agmeka, F., Wathoni, R. N., \& Santoso, A. S. (2019). The Influence of Discount Framing towards Brand Reputation and Brand Image on Purchase Intention and Actual Behaviour in ECommerce. Journal Procedia Computer Science, 161, 851-858. https://doi.org/10.1016/j.procs.2019.11.192

Anizir, \& Wahyuni, R. (2017). Pengaruh Social Media Marketing terhadap Brand Image Perguruan Tinggi Swasta di Kota Serang. Sains Manajemen, 3(2). https://doi.org/10.30656/sm.v3i2.254

Berthon, P. R., Pitt, L., McCarthy, I. P., \& Kates, S. (2007). When Customers Get Clever: Managerial Approaches to Dealing with Creative Consumers. Journal Business Horizons, 50(1), 3947. https://doi.org/10.1016/j.bushor.2006.05.005

Bilgin, Y. (2018). The Effect of Social Media Marketing Activities on Brand Awareness, Brand Image and Brand Loyalty. Business and Management Studies an International Journal, 6(1), 128-148. https://doi.org/10.15295/bmij.v6i1.229

Brogan, C. (2010). Social Media 101: Tactics and Tips to Develop Your Business Online (1st Editio). Wiley.

Bruhn, M., \& Schoenmueller, V. (2012). Are Social Media Replacing Traditional Media in Terms of Brand Equity Creation. Journal Management Research Review, 35(9), 770-790. https://doi.org/10.1108/01409171211255948

Elaydi, H. O. (2018). The Effect of Social Media Marketing on Brand Awareness Through Facebook: An Individuals-Based Perspective of Mobile Services Sector in Egypt. Open Access Library Journal, 5(10), 1-5. https://doi.org/10.4236/oalib.1104977

Foster, B. (2016). Impact of Brand Image on Purchasing Decision on Mineral Water Product "Amidis" (Case Study on Bintang Trading Company. American Research Journals of Humanities and Social Sciences, 2, 1-11. https://doi.org/10.21694/2378-7031.16023

Ghozali, I. (2012). Aplikasi Analisis Multivariate dengan Program IBM SPSS 20. Semarang: Universitas Diponegoro.

Grant, R. (2021). Menggunakan Sosial Media Marketing Untuk Memerluas Target Pasar. Diambil 29 Maret 2021, dari http://bariteritonline.com/menggunakan-sosial-media-marketing-untukmemerluas-target-pasar/, diakses pada 20 Desember 2020.

Gunelius, S. (2011). 30-Minute Social Media Marketing. United States: McGraw Hill. 
Damayanti, et al. Pengaruh Social Media Marketing terhadap Brand Image My Pangandaran Tour and Travel

Karman, M. A. (2015). The Impact of Social Media Marketing on Brand Equity Toward the Purchase Intention of Starbucks Indonesia. iBuss Management, 3(2), 77-88.

Keller, K. L. (2009). Building Strong Brands in a Modern Marketing Communications Environment. Journal of Marketing Communications, 15(2/3), 139-155. https://doi.org/10.1080/13527260902757530

Keller, K. L. (2013). Strategic Brand Management Building, Measuring, and Managing Brand Equity (Fourth Edi). England: Pearson.

Kemp, S. (2019). Digital 2019: Indonesia. New York. (https://wearesocial.com/blog/2019/01/digital2019-global-internet-use-accelerates. Diakses pada 29 Januari 2021)

Kristiani, P., \& Dharmayanti, D. (2017). Pengaruh Social Media terhadap Repeat Purchase dengan Variabel Intervening Perceived Service Quality dan Brand Image pada Industry Fast-Food Restaurant di Surabaya. Petra Business and Management Review, 3(1).

Li, C., \& Bernoff, J. (2011). Groundswell, Expanded and Revised Edition: Winning in a World Transformed by Social Technologies (Revised Ed). Cambridge: Harvard Business Review Press.

Lipsman, A., Mudd, G., Rich, M., \& Bruich, S. (2012). The Power of "Like" How Brand Reach (and Influence) Fans Through Social-Media Marketing. Journal of Advertising Research, 52(1), 357-365. https://doi.org/10.2501/JAR-52-1-040-052

Mambu, E (2015). The Influence Of Brand Image, and Service Quality toward Consumer Purchase Intention of Blue Bird Taxi Manado. Jurnal Riset Ekonomi, Manajemen, Bisnis Dan Akuntansi. $3(4), 645-653$.

Mangold, W. G., \& Faulds, D. J. (2009). Social Media: the New Hybrid Element of the Promotion Mix. Journal Business Horizons, 52(4), 357-365. https://doi.org/10.1016/j.bushor.2009.03.002

Mileva, L., \& Fauzi, A. (2018). Pengaruh Social Media Marketing terhadap Keputusan Pembelian (Survei online pada Mahasisa Sarjana Jurusan Ilmu Administrasi Bisnis Angkatan 2014/2015 Fakultas Ilmu Administrasi Universitas Brawijaya yang Membeli Starbucks Menggunakan $\begin{array}{llll}\text { LINE). Journal } & \text { Administrasi }\end{array}$ https://administrasibisnis.studentjournal.ub.ac.id/index.php/jab/article/view/2421

Nurfitriani. (2016). Pengaruh Social Media Marketing Melalui Official Account LINE Alfamart terhadap Minat Beli Konsumen. Jurnal Online Mahasiswa Bidang Ilmu Sosial dan Ilmu Politik, $3(2), 15-16$.

Perera, G. R., \& Perera, I. (2016). Influence of Social Media Marketing on the Brand Image of Organizations in the Hospitality Industry of Sri Lanka. International Journal of Asian Business and Information Management, 7(1), 12. https://doi.org/10.4018/IJABIM.2016010103

Rayat, A., Rayat, M., \& Rayat, L. (2017). The Impact of Social Media Marketing on Brand Loyalty. $\begin{array}{lllll}\text { Annals of Applied } & \text { Sport } & \text { Science, } & 5(1), & \end{array}$ https://doi.org/10.18869/acadpub.aassjournal.5.1.73

Sallam, M. A. (2016). The Impact of Brand Image and Corporate Branding on Consumer's Choice: the Role of Brand Equity. International Journal of Marketing Studies, 8(1), 98. https://doi.org/10.5539/ijms.v8n1p98

Seo, E.-J., \& Park, J.-W. (2018). A Study on the Effects of Social Media Marketing Activities on 
Brand Equity and Customer Response in the Airline Industry. Journal of Air Transport Management, 66, 36-41. https://doi.org/10.1016/j.jairtraman.2017.09.014

Simamora, Henry (2000). Manajemen Pemasaran Internasional (Jilid I). Jakarta: Salemba Empat.

Sugiyono. (2014). Metode Penelitian Kuantitatif Kualitatif dan R\&D. Bandung: Alfabeta.

Suwena, I. K., \& Widyatmaja, I. G. N. (2017). Pengetahuan Dasar Ilmu Pariwisata (Edisi Revi). Denpasar: Pustaka Larasan.

Wijaya, B. S., \& Putri, D. M. (2013). Is Social Media Impactful for University's brand image? Jurnal Manajemen Teknologi, 12(3), 276-295. https://doi.org/10.12695/jmt.2013.12.3.4

Yadav, M., \& Rahman, Z. (2017). Measuring Consumer Perception of Social Media Marketing Activities in E-Commerce Industry: Scale Development \& Validation. Telematics and Informatics, 34(7), 1294-1307. https://doi.org/10.1016/j.tele.2017.06.001 